\title{
O TRABALHO DO PROFESSOR NO ATENDIMENTO EDUCACIONAL ESPECIALIZADO: VOZES E AFETOS DE UM OFÍCIO
}

\section{THE WORK OF THE TEACHER IN SPECIALIZED EDUCATIONAL SERVICES: VOICES AND AFFECTION OF A PROFESSION}

\author{
Rosycléa Dantas ${ }^{34}$ \\ Dennis Souza da Costa ${ }^{35}$
}

\begin{abstract}
RESUMO: Moita Lopes (2013) e Kleiman (2013) ressaltam a necessidade de abrirmos espaço na Linguística Aplicada (LA) para aqueles indivíduos constituídos em práticas sócio-históricas com menor visibilidade, enquanto ato político ao tematizar realidades ainda marginalizadas na contemporaneidade. Essa mesma necessidade é reconhecida por Medrado e Celani (2017) no que se refere à educação de pessoas com deficiência, ao apontarem que a Linguística Aplicada está sendo convocada para tecer diálogos com a inclusão educacional. Nesse panorama, enquanto linguistas aplicados, buscamos atender essa necessidade refletindo acerca dos processos inclusivos, com foco no Atendimento Educacional Especializado (AEE), ofertado em uma Sala de Recursos Multifuncionais (SRM). De modo mais específico, objetivamos compreender as vozes e os elementos envolvidos no trabalho de uma professora que atua na SRM de uma escola regular da rede pública de ensino, localizada no município de João Pessoa, Brasil. Analisamos qualitativamente a fala da professora que, por meio de uma entrevista, reflete sobre seu fazer educacional no AEE. Para essa discussão, utilizaremos noções advindas das Ciências do Trabalho (CLOT, 2010) e pressupostos teóricos e metodológicos do Interacionismo Sociodiscursivo (BRONCKART, 1999; MACHADO, 2007), destacando as vozes e os elementos que afetam e constituem o trabalho educacional da nossa colaboradora. $\mathrm{O}$ texto produzido pela docente na entrevista evoca um coro de vozes (BRONCKART, 1999) que dialogam entre si, diminuindo e aumentando sua potência de agir (SPINOZA, 2014 [1677]). Além disso, a professora avalia o seu lugar e o lugar social da sala de recursos dentro da escola, destacando a importância desse espaço para o desenvolvimento dos alunos com deficiência, mas também pontuando sua desvalorização, visto que muitos dos que do seu coletivo de trabalho interpretam-no como um lugar de descanso para os alunos e para a professora, e não como ambiente potencial de aprendizagem.
\end{abstract}

PALAVRAS-CHAVE: Inclusão. Atendimento Educacional Especializado. Sala de Recursos Multifuncionais. Interacionismo Sociodiscursivo. Linguística Aplicada.

ABSTRACT: Moita Lopes (2013) and Kleiman (2013) emphasize the need to give attention in Applied Linguistics (LA) to those individuals constituted in socio-historical practices with less visibility, as a political act to thematize realities still marginalized in contemporary times. This same need is recognized by Medrado and Celani (2017) regarding the education of people with disabilities, pointing out that Applied Linguistics is being called upon to dialogue with educational inclusion. In this panorama, as applied linguists, we seek to meet this need reflecting on the inclusive processes, focusing on the Specialized Educational Services (SES), offered in a Multifunctional Resources Room (MRR). More specifically, we aimed at understanding the voices and the elements involved in the work of a teacher at the MRR of a regular public school in the city of João Pessoa, Brazil. We qualitatively analyzed the teacher's speech that, through an interview, reflects on her educational background in the SES. For this discussion, we will use notions from the Labor Sciences (CLOT, 2010) and theoretical and methodological assumptions of Sociodiscursive Interactionism (BRONCKART, 1999; MACHADO, 2007), highlighting the voices and elements that affect and constitute the educational work of our collaborator. The text produced by the teacher in the interview evokes a chorus of voices (BRONCKART, 1999) that dialogue with each other, diminishing and increasing her power to act (SPINOZA, 2014 [1677]). In addition, the teacher evaluates her place and the social place of the resource room within the school, highlighting the importance of this space for the development of students with disabilities, but also indicating the devaluation of her work, since many of those who are part of the collective work interpret it as a place of rest for the students and for the teacher and not as a potential learning environment.

KEYWORDS: Inclusion. Specialized Educational Services. Multifunctional Resources Room. Sociodiscursive Interactionism. Applied Linguistics.

\footnotetext{
${ }^{34}$ Doutoranda em Linguística pela Universidade Federal da Paraíba (UFPB). Professora de Língua Inglesa voluntária do Instituto dos Cegos da Paraíba Adalgisa Cunha (ICPAC) e Professora Substituta no Departamento de Línguas Estrangeiras Modernas (DLEM) na UFPB. Email: rosycleads@hotmail.com

${ }^{35}$ Mestre em Linguística pela Universidade Federal da Paraíba (UFPB). Professor de Língua Inglesa, na Educação Básica III, da rede estadual de ensino da Paraíba. Email: dennis.jppb@hotmail.com
} 


\section{Introdução}

A história da educação das pessoas com deficiência nos mostra que a trajetória escolar desses indivíduos foi marcada, em boa parte, por uma perspectiva segregacionista de ensino (SANTIAGO, 2011; KASSAR, 2013; MARTINS, 2015). Entretanto, a promulgação de políticas educacionais e ações afirmativas nos últimos anos, como a Declaração Mundial de Educação para Todos (UNICEF, 1990), a Declaração de Salamanca (UNESCO, 1994), e o Decreto da Convenção da Guatemala (BRASIL, 2001), tem buscado ressignificar o processo de escolarização das pessoas com deficiência, garantindo-lhes cada vez mais o acesso à rede regular de ensino, em decorrência do entendimento de que "as pessoas devem aprender juntas, independentemente de suas limitações" (MEDRADO, 2014, p. 22). Isso se confirma nos dados do Censo Escolar da Educação Básica que indicam um crescimento significativo no número de matrículas de alunos de 4 a 17 anos com deficiência, transtornos globais do desenvolvimento ou altas habilidades na educação básica, em classes comuns. Em 2003, a educação básica contava com 145.141 matrículas desse público (BRASIL, 2015), enquanto em 2017 esse número chegou a 818.143 alunos (BRASIL, 2018).

Essa nova configuração da rede regular de ensino, resultante das políticas de educação para todos (UNICEF, 1990; UNESCO, 1994), trouxe a necessidade de uma reorganização na oferta do Atendimento Educacional Especializado (AEE), visto que os indivíduos público-alvo desse atendimento se encontram diante de um novo contexto de escolarização. Dentre os aspectos reconsiderados na oferta do $\mathrm{AEE}$, destacam-se a redefinição do caráter desse atendimento, compreendido não mais como uma modalidade de ensino substitutiva à sala regular, mas sim de natureza complementar ou suplementar (BRASIL, 2008), assim como a implantação de Salas de Recursos Multifuncionais (SRM) nas escolas da rede pública de ensino por todo o país, viabilizada pelo Programa Implantação de Salas de Recursos Multifuncionais (BRASIL, 2007).

Neste cenário, filiados ao campo da Linguística Aplicada, ciência de natureza essencialmente anti-objetivista, antipositivista e trans/interdisciplinar, que assume a linguagem como espaço de construção dos indivíduos (MOITA LOPES, 2009), e fundamentados na perspectiva teórico-metodológica do Interacionismo Sociodiscursivo (ISD), conforme expresso em Bronckart (2003 [1999], 2009, 2012) e Machado (2007, 2009), em um diálogo com o campo das Ciências do Trabalho (CLOT, 2007, 2010a, 2010b, 2013), buscamos compreender as vozes e os elementos envolvidos no trabalho de uma professora atuante em uma Sala de Recursos Multifuncionais, implantada em uma escola no município de João Pessoa, Estado da Paraíba, Brasil. Nesse sentido, organizamos nosso estudo conforme descrito a seguir.

Inicialmente, discutiremos o papel das SRM na inclusão de alunos com deficiência, revisitando as legislações que orientam seu funcionamento. Em um segundo momento, conceituaremos alguns pressupostos do ISD e das Ciências do Trabalho que fornecem fundamentos para a discussão aqui empreendida. Posteriormente, traçaremos o percurso metodológico, elencando o perfil da nossa colaboradora, o instrumento de pesquisa utilizado e os procedimentos da geração de dados. Por fim, analisaremos nosso corpus à luz do ISD e das Ciências do Trabalho, ressaltando as vozes e os elementos constitutivos do trabalho docente presentes na fala da professora colaboradora.

\section{As salas de recursos multifuncionais e o processo de inclusão escolar}

Em contexto brasileiro, as salas de recursos multifuncionais são espaços criados a partir de iniciativas do Ministério da Educação/Secretaria de Educação Continuada, Diversidade e Inclusão através do Programa de Implantação de Salas de Recursos Multifuncionais, expresso sob a Portaria Ministerial de $n^{\circ} 13$ (BRASIL, 2007). Dotadas de 
equipamentos de informática, mobiliários e materiais didático-pedagógicos, as SRM têm por objetivo primário a oferta do AEE, de modo complementar ou suplementar, prioritariamente no estabelecimento de ensino do qual o aluno faz parte ou em outra escola de ensino regular, em horário inverso ao de sua escolarização, não sendo, portanto, substitutivo às classes comuns (BRASIL, 2010b).

Nesse cenário, começam a ganhar visibilidade, a partir de 2005, os esforços do Ministério da Educação na implantação de 250 Salas de Recursos Multifuncionais em todo o Brasil. Ao longo dos seis anos subsequentes, isto é, até $2011^{36}$, o número cumulativo de SRM implantadas totalizou exatamente 39.301, sendo os anos de 2008 e 2010 períodos mais representativos nas criações dessas salas, como indica o Gráfico $01^{37}$ a seguir.

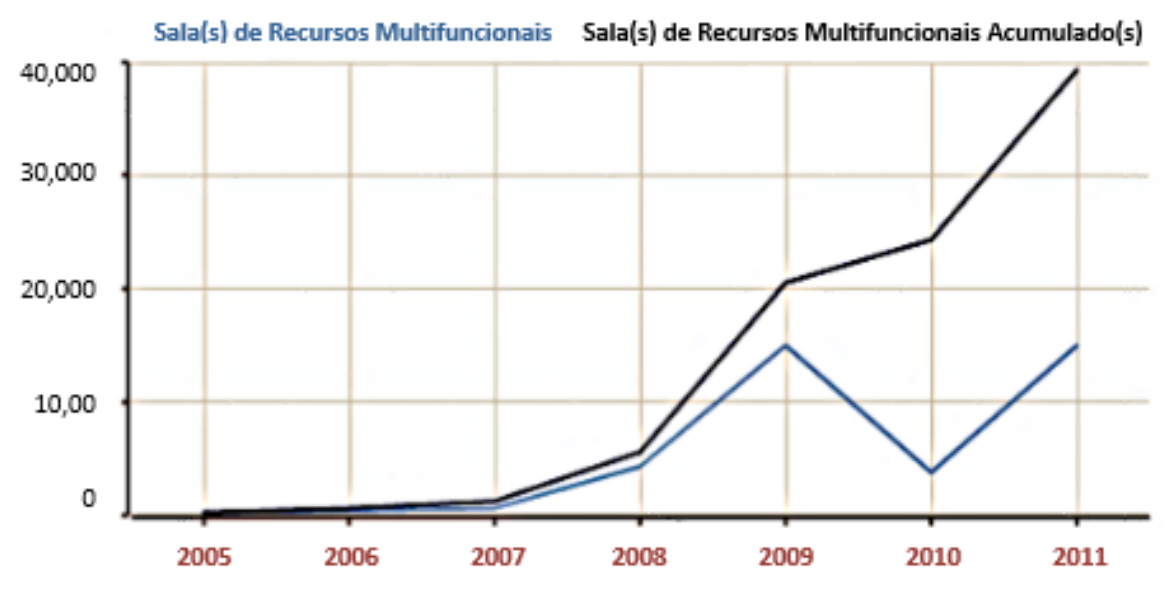

Gráfico 01 - Salas de Recursos Multifuncionais (2005 - 2011)

A maior parte das mais de 39 mil SRM se concentra na região Nordeste, representando quase um terço desse número. Por sua vez, a região Sudeste ocupa o segundo lugar no ranking, apresentando mais de 9 mil SRM. As regiões que contam com menor número de salas implantadas são as regiões Centro-oeste e Norte respectivamente. Esses números estão sintetizados no Gráfico $02^{38}$ adiante.

\section{Número de Salas de Recursos Multifuncionais por região (2005 - 2011)}

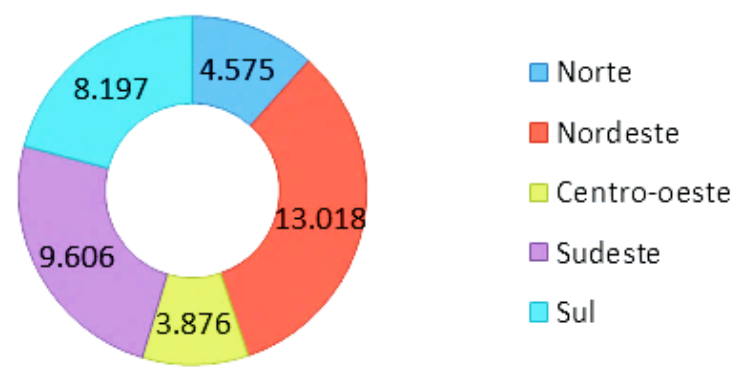

Gráfico 02 - Número de Salas de Recursos Multifuncionais por região (2005 - 2011)

É no Estado da Paraíba, localizado na região com número mais expressivo de SRM, que se encontra implantada a sala de recursos em que atua a colaboradora de nossa pesquisa.

\footnotetext{
${ }^{36}$ Os dados aqui informados são os mais recentes disponibilizados no Portal do Ministério da Educação.

${ }^{37}$ Criado automaticamente a partir da importação de dados disponíveis em $<$ http://painel.mec.gov.br/>.

${ }^{38}$ Elaborado pelos autores com base nos dados disponíveis no sítio $<$ http://painel.mec.gov.br/ $>$.
} 
De acordo com os dados mais recentes disponibilizados no painel $\mathrm{MEC}^{39}$, a Paraíba possui 1.124 SRM, sendo João Pessoa, Campina Grande e Santa Rita os municípios que comportam boa parte desse quantitativo.

Em todo o país, as SRM implantadas são caracterizadas em dois grupos, as de Tipo I e Tipo II. As salas de Tipo I são aquelas com o auxílio de equipamentos, mobiliários e materiais didático-pedagógico, cuja implantação fica dependente da matrícula de alunos público-alvo da educação especial, inseridos nas salas comuns e devidamente registrados no Censo Escolar/INEP ${ }^{40}$. Já as salas de Tipo II, são aquelas equipadas com os mesmos recursos da sala Tipo I, adicionando-se materiais acessíveis específicos para o atendimento de alunos com deficiência visual, cuja implantação fica sujeita a matrícula de alunos deficientes visuais na escola regular, com registro no Censo Escolar/INEP (BRASIL, 2010a).

De acordo com a Política Nacional de Educação Especial na Perspectiva da Educação Inclusiva, constituem-se público-alvo do AEE fornecidos nas SRM: alunos com deficiência, ou seja, aqueles que apresentam "[...] impedimentos de longo prazo, de natureza física, mental ou sensorial"; alunos com transtornos globais do desenvolvimento (TGD), os quais possuem "[...] alterações qualitativas das interações sociais recíprocas e na comunicação, um repertório de interesses e atividades restrito, estereotipado e repetitivo"; e alunos com altas habilidades/superdotação, que são aqueles que demonstram “[...] potencial elevado em qualquer uma das seguintes áreas, isoladas ou combinadas: intelectual, acadêmica, liderança, psicomotricidade e artes", como também podem apresentar "[...] grande criatividade, envolvimento na aprendizagem e realização de tarefas em áreas de seu interesse" (BRASIL, 2008, p.09).

Por sua vez, para atuar no AEE, o profissional precisa ser habilitado para o exercício da docência, com formação continuada em educação especial. O documento orientador do Programa Implantação de Salas de Recursos Multifuncionais (BRASIL, 2010a, p.08-09) indica como atribuições do trabalho do professor do AEE atividades como

\begin{abstract}
Elaboração, execução e avaliação do plano de AEE do estudante; definição do cronograma e das atividades do atendimento do estudante; organização de estratégias pedagógicas e identificação e produção de recursos acessíveis; ensino e desenvolvimento das atividades próprias do AEE, tais como: Libras, Braille, orientação e mobilidade, Língua Portuguesa para alunos surdos; informática acessível; Comunicação Alternativa e Aumentativa - CAA, atividades de desenvolvimento das habilidades mentais superiores e atividades de enriquecimento curricular; acompanhamento da funcionalidade e usabilidade dos recursos de tecnologia assistiva na sala de aula comum e demais ambientes escolares; articulação com os professores das classes comuns, nas diferentes etapas e modalidades de ensino; orientação aos professores do ensino regular e às famílias sobre a aplicabilidade e funcionalidade dos recursos utilizados pelo estudante; interface com as áreas da saúde, assistência, trabalho e outras.
\end{abstract}

Com base nesse documento orientador, vemos que o trabalho do professor de AEE exige desse profissional conhecimentos que lhe permita atender alunos com diferentes necessidades educacionais, como alunos com deficiência, TGD e altas habilidades/superdotação. Além disso, subentende-se que o professor do AEE possua um repertório linguístico variado, conhecendo línguas, códigos e sistemas de comunicação assistiva específicos para o atendimento desse público alvo. Outrossim, podemos dizer que o trabalho do professor do AEE é um trabalho essencialmente coletivo e colaborativo, pois compete a esse profissional atuar de forma articulada com os professores das salas regulares,

\footnotetext{
${ }^{39}<$ http://painel.mec.gov.br/>.

${ }^{40}$ Instituto Nacional de Estudos e Pesquisas Educacionais Anísio Teixeira.
} 
como também com familiares desses alunos e outros profissionais de áreas da saúde, assistência, trabalho, entre outras.

A fim de conhecermos outros aspectos do trabalho dos professores de AEE, e alguns de seus desafios, revisitamos alguns estudos brasileiros que buscaram compreender as atividades realizadas nas SRM por esses profissionais. Heiderscheidt Fuck (2014), ao investigar o atendimento educacional especializado nas salas de recursos multifuncionais, no município de Joinville, a partir das concepções das professoras da sala comum, observou que elas reconhecem a necessidade de refletir sobre o papel da escola no desenvolvimento dos alunos e, especificamente, dos alunos público alvo do AEE. Da mesma forma, as professoras da sala comum demonstram compreender a importância da sala de recursos multifuncionais e sua influência no próprio trabalho que desenvolvem. No entanto, as vozes dessas colaboradoras sugerem que sejam promovidas discussões e reflexões sobre o AEE, a fim de que os professores do ensino regular possam conhecer mais de perto o trabalho desenvolvido nessas salas.

Fróes (2015) buscou analisar, com base tanto nas vozes de professores das salas de recursos quanto das salas regulares, de que maneira o AEE, no munícipio de Porto Alegre, colabora com o processo de escolarização de pessoas com deficiência visual. $O$ autor identificou que o AEE desempenha papel fundamental no processo de inclusão de alunos com deficiência visual, viabilizando um trabalho que corresponde às necessidades de pais, alunos e professores da sala regular. Ao mesmo tempo, foi possível perceber uma desarticulação entre o trabalho desenvolvido pelos professores da sala regular e o professor do AEE.

Nessa mesma direção, o estudo de França (2016), que teve por objetivo compreender como as professoras regentes representam a atividade do professor do AEE no contexto da Educação Infantil, avaliou como positiva a presença do professor de AEE na escola regular, ressaltando diversas mudanças ocorridas nas práticas educacionais a partir da mediação desses profissionais nas atividades realizadas pelas professoras das salas regulares.

Traçadas essas breves reflexões sobre as salas de recursos multifuncionais e a educação inclusiva, e ampliando essa discussão para o campo da Linguística Aplicada que, como destacado por Medrado e Celani (2017), está sendo convocada para discutir questões sobre a inclusão escolar de pessoas com deficiência, apresentaremos a seguir algumas considerações sobre o trabalho docente e seus elementos constitutivos, fundamentadas a partir das Ciências do Trabalho (CLOT, 2007, 2010), do quadro teórico-metodológico do Interacionismo Sociodiscursivo (BRONCKART, 2003 [1999], 2009, 2012; MACHADO, 2007, 2009).

\section{O trabalho docente em diálogo com o Interacionismo Sociodiscursivo e as Ciências do Trabalho}

Nossa base trans/indisciplinar da Linguística Aplicada (MOITA LOPES, 2009) nos permite tecer relações com o Interacionismo Sociodiscursivo (ISD), o qual é definido por Bronckart (2012, p.33) como "uma tentativa contemporânea de continuar a tendência do interacionismo social, cuja figura simbólica é o psicólogo Vygotsky". Com essa perspectiva, o ISD adota quatro princípios, quais sejam:

1. A emergência da linguagem e da história social humana são os dois fatores determinantes do processo de constituição e desenvolvimento [...] 2. Deve haver uma única e integrada ciência humana, porque as habilidades especificamente humanas são produtos de interações entre as dimensões biológicas, psicológicas, sociológicas e linguísticas [...] 3. Essa ciência humana deve ter uma base filosófica sólida e profunda [...] 4. Essa ciência humana deve almejar a utilidade social, o que significa que os problemas educacionais são uma parte integral de seu objeto (BRONCKART, 2012, p.33). 
Esse quarto princípio elencado por Bronckart (op.cit.), que situa as questões educacionais como integrantes do seu objeto de investigação, está intimamente relacionado com a nossa pesquisa sobre o trabalho docente na educação inclusiva. E, assim como o autor preconiza uma utilidade social no quadro do ISD, nosso compromisso com a discussão aqui empreendida tem uma preocupação com problemas reais, vivenciados por uma professora que atua no contexto das Salas de Recursos Multifuncionais. Essas Salas parecem representar o que Reichmann (2015), em um contexto diferente, designou de entrelugar socioprofissional. Um entrelugar no processo de inclusão escolar, na medida em que posicionam o Atendimento Educacional Especializado, até então ofertado apenas pelas instituições de Educação Especial, no desenho da arquitetura da Escola Regular, com papéis e objetivos que ainda se confundem.

Destarte, existe a necessidade de darmos visibilidade para o professor que atua nesse entrelugar, pois se "o trabalho educacional é particularmente opaco" (BRONCKART, 2009, p.172), o trabalho do professor que atua nas SRM o é ainda mais.

Revestido desse compromisso com a educação, Bronckart (2009, p.161) ressalta que precisamos "(re) valorizar a profissão do professor e essa (re) valorização requer que sejam conhecidas, compreendidas e clarificadas as questões que estão em jogo, a significação e as condições de realização desse 'métier' particular que é o ensino". Pensando na nossa pesquisa, buscamos, igualmente, conhecer, compreender e clarificar algumas questões que estão em jogo no trabalho docente realizado no contexto específico de uma Sala de Recursos Multifuncionais brasileira, assim como os significados e as condições de realização desse métier. Para empreender esse processo investigativo, dialogamos, como também o faz Bronckart (2009), com conceitos advindos das Ciências do Trabalho (CLOT, 2007), em especial com os da Clínica da Atividade (CLOT, 2010a, 2010b, 2013).

Nesse diálogo, adotamos o entendimento de coletivo discutido por Clot (2010a, 2013). Segundo o autor, nem todo trabalho coletivo, isto é, de um grupo de trabalhadores, implica um coletivo de trabalho, pois esse coletivo "não é apenas um 'pertencimento' a adotar, mas um instrumento de trabalho pessoal, para usar e cuidar em conjunto" (CLOT, 2013, p.9). Sendo um instrumento de trabalho, ele necessita ser cuidado para que esteja "disponível" para uso "em boas condições" (OSÓRIO, 2015, p.85), caso contrário, a saúde dos profissionais se degrada e o coletivo "reduz-se, então, a uma reunião de indivíduos expostos ao isolamento: o trabalho coletivo é, então, privado de coletivo de trabalho" (CLOT, 2010a, p.170). Cuidar do ofício se configura, portanto, como um gesto individual e coletivo indispensável para sua manutenção e desenvolvimento.

Ainda de acordo com Clot (2010b, p.222), cuidar do trabalho tem um duplo sentido: "transformar o trabalho, mas também, em francês, fazer um bom trabalho, é a qualidade do trabalho bem feito que é uma fonte de saúde". A transformação das condições de desenvolvimento da atividade, para que possibilite a realização de um trabalho com qualidade, é algo conjunto, tendo em vista que a responsabilidade de cuidar do ofício é de todos, e contínuo, pois, como nos lembra Clot (CLOT, 2013, p.8), "no trabalho, a saúde exige uma reciprocidade que não seja somente uma reciprocidade de "urgência"". Em outras palavras, a vida do ofício necessita ser regada dia após dia e não somente nos momentos de crise, pois sem esses cuidados, os trabalhadores podem ficar "entregues a si mesmos em uma situação que se degrada, amputados em sua capacidade de agir, em sofrimento psíquico" (OSÓRIO, 2015, p.85).

Nessa linha de discussão e com base no pensamento spinozano, Clot (2010a) ressalta que a atividade de trabalho é afetada pelos outros e pelo próprio trabalhador, em um jogo de afetos que pode aumentar ou diminuir o poder de agir dos trabalhadores. Quando o oficio é 
afetado pela falta de cuidados, o poder de agir dos envolvidos tende a diminuir, porém, esse mesmo conflito/sofrimento, que reduz a agência do trabalhador, pode ser fonte de desenvolvimento, dependendo, segundo Clot (2007, p.179), "da maneira como a ação em curso enfrenta os conflitos".

\section{Procedimentos metodológicos em uma perspectiva interacionista sociodiscursiva}

Partindo do entendimento de que "a pesquisa só é pertinente na medida em que se situa em um contexto" (MORIN, 2013, p.59), situamos nossa investigação no contexto específico de uma Sala de Recursos Multifuncional, localizada no interior de uma escola pública, na cidade de João Pessoa, Estado da Paraíba, Brasil.

A fim de alcançarmos nosso objetivo e compreendermos melhor esse contexto de pesquisa, optamos por uma entrevista semi-estruturada como instrumento de geração dos dados. A entrevista foi realizada na SRM em que nossa colaboradora atuava, no dia $04 \mathrm{de}$ agosto de 2016. O dia e o horário foram escolhidos por ela e a entrevista teve duração de $37 \mathrm{~min} 58 \mathrm{seg}$.

A professora colaboradora da pesquisa, por questões éticas identificada com o pseudônimo de Helen, tinha, na época da entrevista, 07 anos de exercício da profissão no âmbito da Sala de Recursos Multifuncional. Antes de atuar na SRM, Helen lecionava na mesma escola como professora de Geografia. Sua entrada na SRM foi acompanhada de cursos de capacitação com temáticas diversas, das quais a professora mencionou: Atendimento Educacional Especializado, Transtorno Global do Desenvolvimento, Libras e Deficiência Visual. Os cursos foram realizados por uma instituição de apoio à pessoa com deficiência no estado da Paraíba, somando um total de 180 horas.

A SRM, contexto de atuação de Helen no ano da pesquisa, recebia 48 alunos com deficiência, porém apenas 30 frequentavam regularmente. Desses 30 alunos, Helen acompanhava metade e a outra metade era de responsabilidade do seu colega de trabalho na SRM. O atendimento, geralmente realizado no horário oposto ao das aulas dos alunos, era feito de maneira individual ou em dupla.

Com relação aos procedimentos de análise, faremos a interpretação da voz da professora Helen partindo dos seguintes aspectos do Interacionismo Sociodiscursivo: as vozes e os elementos constitutivos do sistema de atividade do professor.

As vozes são classificadas por Bronckart (2003 [1999]) como: vozes de personagens, vozes sociais e voz do autor empírico. As vozes de personagem dizem respeito às pessoas ou entidades implicadas, na qualidade de agentes, ao conteúdo temático do texto. As vozes sociais são aquelas de personagens, grupos ou instituições sociais que se apresentam como avaliações externas ao conteúdo temático e, por sua vez, a voz do autor empírico marca a voz da pessoa que está na origem da produção textual, respondendo como agente do que é enunciado. De acordo com Machado e Bronckart (2009), essas vozes podem ser explícitas identificadas por marcadores (discurso direto e indireto, discurso segundo, aspas, etc.) e implícitas - analisadas através de organizadores argumentativos e unidades de negação de asserção.

Os elementos constitutivos do sistema de atividade do professor são apresentados por Machado (2007). Segundo a autora, o trabalho do professor envolve um indivíduo (o próprio docente) que, situado em um contexto sócio histórico particular, age sobre o meio, em interação com diferentes outros (pais, alunos, colegas...), com prescrições advindas de diversas instâncias (do sistema educacional, de ensino e didático), servindo-se de artefatos, dos quais ele se apropria como instrumentos para a criação do meio aula.

Vejamos, na seção seguinte, a análise de 07 segmentos de falas da professora Helen, nessa perspectiva sociointeracionista. 


\title{
5 Vozes e elementos constitutivos do agir docente no AEE
}

Iniciamos nossa interpretação dos dados, ressaltando que a professora Helen tece suas reflexões em diálogo com os atores sociais que compõem seu ofício, isto é, buscando resgatar, por meio de uma orquestra de vozes (BRONCKART, 2003 [1999]), o coletivo de trabalho. Nas falas da professora Helen, o coletivo de trabalho se apresenta no centro das suas reflexões, retomando a ideia do coletivo como instrumento para o trabalho, defendida por (CLOT, 2010a). Vejamos como ela explicita essa discussão, ao falar do lugar da Sala de Recursos Multifuncional, dentro da escola:

\section{Segmento 01}

Eu acho que é de suma importância a sala do AEE na escola [...] a sala do AEE é para fazer essa ponte entre o professor de sala de aula e aqui, os dois têm que trabalhar juntos, então como seria? Na minha opinião a proposta é o quê? Os dois têm que trabalhar juntos, os dois têm que planejar juntos né, têm que planejar juntos.

Ao ressaltar a necessidade de trabalho coletivo, Helen traz duas vozes de personagem, a voz do professor da sala regular e do professor da SRM, que oferece o Atendimento Educacional Especializado. Essa relação colaborativa de trabalho entre os docentes retoma a prescrição do "Manual de Orientação: Programa de Implantação de Sala de Recursos Multifuncionais" que estabelece como atribuição do professor do AEE "articulação com os professores das classes comuns" (BRASIL, 2010, p.09). Essa prescrição legal, assumida por Helen sobre o ofício do professor da escola regular e o professor da SRM, é marcada pela modalização deôntica ${ }^{41}$ "têm que". Apesar dessa prescrição, ela relata que o trabalho coletivo entre os docentes da sala regular e da SRM não ocorre na escola em que atua:

\begin{abstract}
Segmento 02
aqui no XXX (escola em que trabalha) mesmo nunca aconteceu esse planejamento [...] acontece assim, você o corpo a corpo, você individualmente falar com um professor, com outro [...] mas aí a maioria deles querem o quê? Que você assuma aquele aluno, que você faça a atividade dele [...] então aqui falta muito isso, mas se realmente tivesse essa parceria, esse/essa sintonia né, entre, essa comunicação entre esses professores né, professor de sala de aula, professor de sala de recursos, a coisa com certeza andaria bem melhor.
\end{abstract}

No segmento 02, além da voz do professor, Helen mobiliza a voz dos alunos com deficiência (vozes de personagem), ressaltando que não ocorre um trabalho de "parceria" entre os docentes para que o desenvolvimento desses alunos seja efetivado. Os professores das salas regulares, parte dos outros que compõem os elementos constitutivos do agir da professora Helen, parecem, em sua maioria, não assumirem a responsabilidade com os alunos com deficiência, na medida em que esperam que a professora da SRM, Helen, "assuma" esses alunos. Nesse caso, a função do coletivo como um instrumento para o trabalho (CLOT, 2010a) da nossa colaboradora, aparenta ainda não funcionar. Essa responsabilidade, muitas vezes não assumida pelo coletivo de trabalho, é destacada pela professora ao mobilizar a voz da família dos alunos, vejamos:

\section{Segmento 03}

Alguns pais não estão trazendo. Eu mesmo tenho cinco alunos que não estão vindo, porque há dificuldade dos pais de trazer. Tem atendimento externo [...] aí não estão trazendo [...] tem outra questão também que alguns pais, algumas famílias, elas/eu percebo que elas não valorizam o atendimento na sala de recursos dentro da escola.

\footnotetext{
${ }^{41}$ Avaliação efetuada “[...] do domínio do direito, da obrigação social e/ou da conformidade com as normas em uso" (BRONCKART, 2012 [1999], p.331).
} 
A família dos alunos é um dos elementos que compõem o sistema de trabalho docente e, no caso descrito por Helen, a participação da família é fundamental para que o trabalho na Sala de Recursos funcione, uma vez que é ela a responsável por levar o aluno para a instituição, no contraturno escolar. Alguns pais/responsáveis não cumprem essa demanda, conforme relatado pela docente, que elenca algumas questões como: os alunos, na cidade de João Pessoa, podem realizar atividades de AEE em outros espaços (atendimento externo, mencionado por Helen), a exemplo da Fundação Centro Integrado de Apoio à Pessoa com Deficiência - FUNAD e do Instituto dos Cegos da Paraíba Adalgisa Cunha - ICPAC; alguns pais/responsáveis têm dificuldades por conta de trabalho no contraturno e de questões financeiras para deslocamentos para escola; e outros, como destacado por Helen, não valorizam o atendimento na Sala de Recursos, dentro da escola. Assim, na escola aqui descrita pela colaboradora, a família parece nem sempre cumprir o papel que lhe é requerido diante de um contexto de AEE.

Essa falta de cuidado com o ofício (CLOT, 2010a), por parte de diversos membros do coletivo, afeta a professora Helen de maneira negativa, provocando sofrimento e adoecimento.

\begin{abstract}
Segmento 04
aqui eu sou conhecida como professora estressada, já fui chamada de doida aqui também, já fui chamada de doida é... já adoeci. Uma vez aqui eu tive que tirar uma licença [...] já fui até internada mesmo, fui pra XXX (hospital) e quando o médico olhou lá disse que era um nível de estresse, era alto nível de estresse, então assim, aqui precisa melhorar muito, porque aqui funciona muito assim, cada um no seu quadrado, sabe.
\end{abstract}

Helen mobiliza a voz da escola, do seu coletivo que a representa como "estressada" e "doida". Retomando aqui o pensamento de Spinoza (2014 [1677]), de que afetos negativos diminuem a potência de agir do indivíduo, Helen tem sua potência de agir reduzida, o que nos é revelado por meio da internação no hospital. Nesse cenário, a professora traz a voz de personagem de um membro de outro coletivo de trabalho, o médico, que diante do adoecimento de Helen, passa a transitar no ofício da docente como alguém que vem auxiliar na sua recuperação e volta ao trabalho. A presença do médico na fala de Helen, ressalta, outrossim, como os outros que afetam o ofício docente são múltiplos, o que torna o sistema de trabalho do professor uma rede complexa, constituída e perpassada por diversos fios, advindos do próprio métier e de fora, de ofícios outros.

Nessa rede de afetos, ou nas palavras de Clot (2013), "jogo de afetos", vejamos como a diminuição da potência do agir de Helen faz com que ela desista de trabalhar em uma instituição que sempre foi o contexto de exercício da sua profissão.

\footnotetext{
Segmento 05

É cada um no seu quadrado e tem professores realmente que adéqua a atividade, mas têm outros que não fazem isso, têm outros que o professor da sala de recursos, aquele aluno com deficiência a responsabilidade é só dele [...] então é um dos motivos também que assim, que eu estou saindo. Eu tô pensando em sair no final do ano da escola, em dezembro. Eu pedi pra sair agora em julho. O quê adianta? Eu já tinha falado tanto. Aí eu fui. Eu acho que eu absorvo muito pra mim, aí ele disse que deixasse para o final do ano.
}

No trecho "O quê adianta? Eu já tinha falado tanto", percebemos nesse segmento o quanto Helen está cansada de tentar que o coletivo funcione para além de "uma reunião de indivíduos expostos ao isolamento" (CLOT, 2010a, p.170), uma tentativa para que os quadrados, que isolam os professores, tenham suas fronteiras rompidas e o processo de ensino-aprendizagem dos alunos com deficiência seja assumido por todos da comunidade 
escolar. Acreditamos que "um dos motivos" pelos quais ela está saindo da escola em que trabalha está atrelado aos comentários depreciativos dos seus colegas de ofício (vide Segmento 04), o que reitera a necessidade de olharmos não apenas para o trabalhador diante do seu ofício, mas também para o coletivo que o constitui. Nesse momento, percebemos o quanto a ausência de um coletivo como instrumento de trabalho (CLOT, 2010a) pode ser fonte de impedimento para o desenvolvimento profissional dos indivíduos. Apesar dessa configuração coletivo-colaborativa não se estruturar de maneira efetiva, Helen ressalta que:

\section{Segmento 06}

Por parte dos profissionais, a sala de recursos é o lugar que o professor não trabalha [...] que aqui não funciona [...] mas têm alguns professores que elogiam, que acreditam, que acham que é por esse caminho.

Helen também traz a voz de professores que "elogiam", que "acreditam" no seu trabalho. Percebemos então que há, por parte de alguns colegas, o reconhecimento da utilidade e da eficácia do ofício de Helen, o que, como nos lembra Dejours (2005) e Clot (2010a), é de fundamental importância para que ela também se reconheça em seu métier, para que sinta que seu trabalho é útil. Esse é o desejo de Helen, como explicitado no segmento abaixo:

\section{Segmento 07}

Com relação ao trabalho em si eu me sinto uma pessoa realizada, com minhas dificuldades, com minhas limitações também, mas eu sempre busco [...] quando eu não estiver mais aqui eu espero ter deixado algum legado aqui.

No segmento 07 , constituído pelo pela voz da professora enquanto autora empírica do texto, e marcada linguisticamente pelo pronome "eu", Helen, disposta a sair da escola no final do ano letivo, relata que espera deixar "algum legado", ou seja, espera que seu trabalho tenha feito a diferença no processo educacional daquela instituição. Esse desejo de Helen pela realização de um trabalho que valha à pena ser feito, permite, outrossim, que ela se sinta "realizada", apesar das "dificuldades" e das "limitações" que encontra. Essa fala de Helen reforça o entendimento de Clot (2010a) de que quanto mais o trabalhador é afetado negativamente pela falta de reconhecimento no ofício, maior será o seu desejo de se reconhecer no que faz e de obter esse reconhecimento por outros.

\section{Algumas considerações}

Compreendemos que Helen destaca a responsabilidade dos atores sociais que compõem o seu ofício docente, reforçando a necessidade de um coletivo como instrumento de trabalho. Ela convoca um coro de vozes (professores, profissionais da escola, gestores, familiares, alunos, médicos), para textualizar que parece existir uma falta de compressão acerca do papel do professor da Sala de Recursos, uma vez que muitos dos seus colegas de trabalho verbalizam que a responsabilidade pela educação dos alunos com deficiência é apenas dela. Helen também é afetada pela falta de valorização do seu ofício, tendo em vista a representação de membros do coletivo, de que a SRM é um lugar de descanso para os alunos e para a professora e não um espaço potencial para aprendizagens e desenvolvimento.

Nesse cenário de afetos negativos, Helen nos apresenta uma professora que adoeceu e teve seu poder de agir diminuído, mediante a falta de cuidados do ofício pelos outros 
personagens que fazem parte dele (colegas professores, gestores, familiares dos alunos, etc.). Diante desses conflitos, ela busca não perder a alegria e o valor do seu trabalho no AEE. Essa discussão nos provoca a reforçar a importância, mencionada por Clot $(2010,2013)$, de se ter boas condições de saúde no trabalho, para que o trabalhador-professor possa se reconhecer verdadeiramente na docência que exerce, com autoestima e admiração. Destarte, convocamos todos, da comunidade em geral, e cada um que faz parte do trabalho docente a cuidar desse ofício, para que ele seja um recurso para a saúde do professor, motivo de prazer e realização, e não uma fonte de doença.

Por fim, afetados pelas reflexões tecidas por Helen, ressaltamos a necessidade de mais pesquisas que possam clarificar outras questões que estão em jogo no trabalho docente opaco e complexo, realizado no contexto específico das SRMs, assim como os significados e as condições de realização desse métier que, ainda, se apresenta em um entrelugar no processo de educação das pessoas com deficiência.

\section{Referências}

BRASIL. Ministério da Educação. Censo escolar da educação básica 2013: resumo técnico. Brasília: MEC/INEP, 2014. Disponível em: <http://portal.inep.gov.br/resumos-tecnico>. Acesso em: 12 jan. 2017.

Ministério da Educação. Decreto no 3.956 de 08 de outubro de 2001. Promulga a Convenção interamericana para a eliminação de todas as formas de discriminação contra as pessoas portadoras de deficiência. Guatemala: 2001. Disponível em: $<$ http://www.planalto.gov.br/ccivil_03/decreto/2001/d3956.htm>. Acesso em: 23 jan. 2017. . Ministério da Educação. Manual de orientação: programa de implantação de sala de recursos multifuncionais. Brasília: Ministério da Educação, 2010a. Disponível em: $<$ http://portal.mec.gov.br/secretaria-de-educacao-especial-sp-598129159>. Acesso em: 04 jan. 2017.

. Ministério da Educação. Nota Técnica - Seesp/Gab/no 11/2010. Brasília: Ministério da Educação, 2010b. Disponível em: <http://portal.mec.gov.br/secretaria-deeducacao-especial-sp-598129159>. Acesso em: 12 jan. 2017.

. Ministério da Educação. Política Nacional de Educação Especial na Perspectiva da Educação Inclusiva. Brasília: MEC/SEESP, 2008. Disponível em: $<$ http://portal.mec.gov.br/secretaria-de-educacao-especial-sp-598129159>. Acesso em: 22 jan. 2017.

. Ministério da Educação. Portaria normativa n 13, de 24 de abril de 2007. 2007. Disponível em:

$<$ http://portal.mec.gov.br/index.php?option=com_docman\&view $=$ download\&alias=9935portaria-13-24-abril-2007\&category_slug=fevereiro-2012-pdf\&Itemid=30192>. Acesso em: 21 jan. 2017.

. Número de pessoas com deficiência em escolas comuns cresce 381\%. 2015.

Disponível em: <http://portal.mec.gov.br/ultimas-noticias/211-218175739/30821-em-12anos-numero-de-pessoas-com-deficiencia-nas-escolas-comuns-cresceu-382>. Acesso em 15 out. de 2017.

. Notas Estatísticas: Censo Escolar 2017. MEC/INEP: Brasília, 2018.

$\overline{B E Y E R}$, H. O. Educação especial e inclusão: um olhar sobre a história e os paradigmas. In: Inclusão e Avaliação na escola de alunos com necessidades especiais. 2ed. Porto Alegre: Mediação, 2006. p.11-26.

BRONCKART. J. P. A linguagem no centro dos sistemas que constituem o ser humano. WITTKE, C. I. (Org.). Gêneros textuais: perspectivas teóricas e práticas. Pelotas: Universidade Federal de Pelotas, 2012. 
Atividade de linguagem, textos e discursos: por um Interacionismo

Sociodiscursivo. São Paulo: Educ, 2012 [1999].

Ensinar: um "métier" que, enfim, sai da sombra. In: MACHADO, Anna Rachel

(Org.). Linguagem e educação: o trabalho do professor em uma perspectiva. São Paulo:

Mercado de Letras, 2009.

CLOT, Y. A função psicológica do trabalho. Petrópolis, RJ: Vozes, 2007.

. A psicologia do trabalho na França e a perspectiva da clinica da atividade. In:

Fractual: Revista de Psicologia, v.22, n.1, p.207-234, 2010 b.

O ofício como operador de saúde. Cadernos de Psicologia Social do Trabalho, v.

16, especial, p. 1-11, 2013.

. Trabalho e poder de agir. Belo Horizonte: Fabrefactum, 2010a.

DEJOURS, C. O fator humano. Trad. Maria Irene S. Betiol; Maria José Tonelli. Rio de Janeiro: Editora FGV, 2005.

FRANÇA, M. G. O trabalho colaborativo com a professora de educação especial: o que dizem as professoras regentes? In: . As complexas tramas da inclusão escolar: o trabalho do professor de educação especial. Jundiaí: Paco Editorial, 2016, p.115-123.

FRÓES, M. A. M. A escolarização das pessoas com deficiência visual: contribuições e limites das atividades pedagógicas mediadas na sala de integração e recursos visual. 2015. 131f. Dissertação (Mestrado em Educação) - Universidade Federal do Rio Grande do Sul, Porto Alegre, 2015.

HEIDERSCHEIDT FUCK, A. O atendimento educacional especializado nas salas de recursos multifuncionais na concepção dos professores da sala comum. 2014. 190f. Dissertação (Mestrado em Educação) - Universidade da Região de Joinville, Joinville, 2014. KASSAR, M. C. M. Uma breve história da educação das pessoas com deficiências no Brasil. In: MELETTI, S. M. F.; . (Orgs.). Escolarização de alunos com deficiências: desafios e possibilidades. Campinas, SP: Mercado de Letras, 2013. p.33-76. MACHADO, A. R. Por uma concepção ampliada do trabalho do professor. In: GUIMARÃES, A. M. M. et al. (Orgs.). O Interacionismo Sociodiscursivo: questões epistemológicas e metodológicas. São Paulo: Mercado de Letras, 2007. p.77-100.

; BRONCKART, J. P. (Re-)configurações do trabalho do professor construídas nos e pelos textos: a perspectiva metodológica do grupo ALTER-LAEL. In: CRISTOVÃO, V. L. e ABREU-TARDELLI, L.S. (Orgs.). Linguagem e educação: o trabalho do professor em uma nova perspectiva. São Paulo: Mercado de Letras, 2009. p.31-75.

MARTINS, L. A. R. História da educação de pessoas com deficiência: da antiguidade ao início do século XXI. Campinas, SP: Mercado de Letras, 2015.

MEDRADO, B. P. Diálogos, ações e desafios: os caminhos de um projeto de pesquisa. In:

(Org.). Deficiência visual e ensino de línguas estrangeiras: políticas, formação e ações inclusivas. Campinas, SP: Pontes Editores, 2014. p.21-31.

MEDRADO, B. P. CELANI, M. A. A. Situando questões de inclusão em uma cartografia da formação de professores de línguas estrangeiras no Brasil. In: MEDRADO, B. P. CELANI, M. A. A. (Orgs.). Diálogos sobre inclusão: das políticas às práticas na formação de professores de línguas estrangeiras. São Paulo: Pontes, 2017.

MOITA LOPES, L. P. Da aplicação de linguística a linguística aplicada indisciplinar. In: PEREIRA, R. C. e ROCA, P. (Orgs.). Linguística aplicada: um caminho com diferentes acessos. São Paulo: Contexto, 2009.

MORIN, E. Educação e complexidade: os sete saberes e outros ensaios. São Paulo: Cortez, 2013.

RABARDEL, P. Les hommeset les Technologies: Approche cognitive des instruments contemporains. Paris: Armand Colin, 1995. 
REICHMANN, C. L. Letras e letramentos: escrita situada, identidade e trabalho docente no estágio supervisionado. São Paulo: Mercado de Letras, 2015.

OSÓRIO, C. Pesquisa e intervenção em clínica da atividade: a análise do trabalho em movimento. In: BENDASSOLI, P. F.; SOBOLL, L. A. (Orgs.). Métodos de pesquisa e intervenção em psicologia do trabalho: clínicas do trabalho. São Paulo: Atlas, 2014.

SANTIAGO, S. A. S. A história da exclusão das pessoas com deficiência: aspectos sócioeconômicos, religiosos e educacionais. João Pessoa: Editora UFPB, 2011.

SPINOZA, B. Ética. Belo Horizonte: Autêntica, 2014 [1677].

UNESCO. Declaração de Salamanca sobre princípios, políticas e práticas na área das necessidades educativas especiais. 1994. Disponível em:

$<$ http://portal.mec.gov.br/seesp/arquivos/pdf/salamanca.pdf $>$. Acesso em: 11 set. 2017.

UNICEF. Declaração Mundial de Educação para Todos. 1990. Disponível em:

$<$ https://www.unicef.org/brazil/pt/resources_10230.htm>. Acesso em: 28 set. 2017.

Submetido em 28/09/18

Aceito em 14/12/2018 